Driving a Career in Tehran: Experiences of Female Internet Taxi Drivers

\begin{abstract}
This qualitative study, explores the career experiences of 34 female internet taxi drivers (FTDs) in Tehran, the capital city of Iran — a developing Muslim-dominant countryand responds to the call for international and contextual perspectives on careers. We adopt the intelligent career framework and the institutional logics perspective to understand the FTDs' career given their institutional context. First, we shed light on why (i.e., financial needs, flexibility, passion for driving, and having social relationships), how (i.e., preferring female passengers, driving skills, improving navigation skills, becoming masculine, accessing a car, and developing self-protection strategies) and with whom (i.e., internet-based taxi company, passengers, family, and citizens) our participants work. Then, we illustrate that normative (e.g., traditional division of labor) and structural (e.g., economic hardship) forces constrain and drive why, how, and with whom the FTDs navigate their career. Our findings unpack an emerging career as it unfolds in an unconventional career context and extends the boundaryless career perspective to examine nonprofessional independent contract workers.
\end{abstract}

Keywords: intelligent career; boundaryless career; taxi driver; Iran; Tehran; qualitative. 


\section{Driving a Career in Tehran: Experiences of Female Internet Taxi Drivers}

\section{Introduction}

Recently, an increasing number of female citizens of a capital city, Tehran, in the heart of a developing Muslim-dominant country, Iran, joined the world-wide pool of internet taxi drivers. This phenomenon is revolutionary for two major reasons. First, driving a taxi is a male-dominant job in most countries, including the West; for example, in London and New York, only $2.2 \%$ and $4 \%$ respectively of taxi drivers have been reported to be female (Newall, 2015; Shatiel, 2016). The increasing interest and fast pace of females entering this occupation, in a context repeatedly reported to be male dominant (Moghadam, 2003) and gender segregated (Metcalfe, 2006), is remarkable. Second, although Iranian women have had the right to drive for approximately eight decades, with $17 \%$ of drivers in Tehran being female (Mehrnews, 2015), after Iran's Islamic Revolution of 1979, formal female taxi driving was limited to a single small-scale company that recruited female drivers and served womenonly customers (2006 to 2013) (Bricke, 2008; Mehrkhane, 2017).

Upon the rise and prevalence of internet-based taxi companies worldwide (e.g., Uber), similar services were initiated in Tehran in 2014 (Kamali Dehghan, 2017). Such taxi services use a mobile application to connect passengers and drivers, offer cheaper prices, monitor the rides and transactions virtually via central offices, and now dominate the taxi transportation market (Gaskell, 2017). As of 2014, just one of the internet-based taxi companies in Iran hosted more than five million registered passengers (in Tehran and three other major cities) as well as 100,000 drivers. These internet-based taxi companies launched women-only services that require female drivers in the city of Tehran (Kamali Dehghan, 2017) whose career experiences have yet to be explored.

In this study, we respond to the call for international and contextual perspectives on careers (Chudzikowski et al., 2011; Khapova \& Arthur, 2011; Mayrhofer, Meyer, \& Steyrer, 
2007; Tams \& Arthur, 2010) and explore what it means to be a female internet taxi driver (FTD) in an understudied context. Our study fits Bamberger and Pratt's (2010) description of unconventional research by being based in the Muslim-dominant developing country of Iran. Iran is characterized by having strong family ties (Javidan \& Dastmalchian, 2003), an oil- and gas-dependent economy (Dastmalchian, Javidan, \& Alam, 2001), a male-dominant workforce (13.4\% of all women older than 10 years old are employed; Statistical Center for Iran, 2018), and a shifting society from traditional to modern in urban areas (Gheissari, 2009). All such characteristics offer a rich context for understanding careers in their context.

The motivation for this study is to address two theoretical gaps in the career literature. First, internet taxi drivers work as independent contractors who do not have formal employment relationships with taxi service companies, own their equipment, exercise economic independence, and control their work schedules (Esbenshade \& Shifrin, 2018; Occhiuto, 2017). As a contract worker, an internet taxi driver, whose sequence of work experiences is independent from an employer, can be a career actor with a boundaryless career (Arthur \& Rousseau, 1996). Although the literature has introduced independent contract work as a representative type of a boundaryless career, very few studies have empirically examined contract workers' careers (Arthur, Khapova, \& Richardson, 2017; DeFillippi \& Arthur, 1994). To examine our participants' careers, we adopt the intelligent career framework, which was originally developed to elucidate boundaryless careers (DeFillippi \& Arthur, 1994, 1996; Parker, Khapova, \& Arthur, 2009). We take a stance counter to the existing empirical research based on the intelligent career framework, which has so far focused on professional career actors. Specifically, we examine nonprofessional career actors whose career does not require high investments in education or training and seek to understand what constitutes their boundaryless career. Addressing the second theoretical gap, there exists limited empirical research regarding the role of institutions in the 
construction of a boundaryless career (Tams \& Arthur, 2010). In this study, we adopt the institutional logics perspective (Friedland \& Alford, 1991; Thornton, Ocasio, \& Lounsbury, 2012) to explore institutional forces impacting the boundaryless career of our participants.

The purpose of this study is to extend the boundaryless career literature to explore career contingencies of nonprofessional contract workers, namely female internet taxi drivers, as impacted by institutional forces. Our findings contribute to career scholarship in three ways. First, we unpack an emerging career as it unfolds in an unconventional career context. Second, we extend the boundaryless career perspective to examine nonprofessional independent contract workers whose career has not been examined through a contemporary career lens. In doing so, we reveal some previously nonidentified factors related to the three ways of knowing (why, how, and with whom). Third, we show that the meaning of why, how, and with whom depends on their institutional context.

\section{Literature Review}

\section{Internet Taxi Driving Careers in Context}

In recent years, internet-based taxi companies are changing how people travel and live in cities (Cramer \& Krueger, 2016). After Uber was introduced in the United States in 2010, other countries initiated similar services, such as DiDi in China, 99 in Brazil, Ola Cabs in India, and Snapp in Iran (Bond, 2014; Carson, 2018; Kamali Dehghan, 2017). These internetbased taxi services are also changing the dynamics of taxi driving careers including the gender roles, which have historically been extremely male-dominant (Roche et al., 2016). For example, in New York City—where $98.9 \%$ of cab drivers are men — the application SheRides was launched to offer female passengers female-only drivers (Forde, 2014). Similarly, the emergence of internet-based taxi services enabled a fleet of female drivers in Tehran (Kamali Dehghan, 2017) that can provide service to both male and female passengers. 
The few studies that have examined female taxi drivers are not recent (e.g., Boyd, 1997; Khosa, 1997; Westmarland \& Anderson, 2001). Even less is known about female drivers working in the emerging internet-based taxi companies (Malin \& Chandler, 2016). Previous studies suggest that the local context (e.g., institutions and regulations) impact taxi drivers' work experiences (Esbenshade \& Shifrin, 2018; Esbenshade, Shifrin, \& Rider, 2018). Therefore, to study internet taxi driving as a new career path for women, we need to consider the context within which such careers evolve.

Literature suggests that regardless of profession, in the context of our study, Iran, the cultural and religious values, emphasizing women's traditional roles as wives and mothers, impose constraints on women careers (Ahmad-Nia, 2002; L. Karimi, 2009). Specifically, studies have reported that Iranian professional women face barriers such as hitting a glass ceiling, a lack of role models, and gender discrimination. However it is important to note that such barriers share similarities to women professionals in the UK, the USA, Canada and other countries that espouse equal employment regulations (Ghorbani \& Tung, 2007). Despite such hindrances, in recent years, career activities of women have improved in Iran as the society has begun to transition from traditional to modern (Bahramitash \& Hooglund, 2011). Notable transitions include an accelerated rise of women's participation in the workforce and pursuit of higher education (Bahramitash \& Salehi Esfahani, 2009).

However, the existing literature based on research conducted in Iran primarily concentrates on women with university degrees and professional careers (e.g., managerial and educated entrepreneurs) (Ghorbani \& Tung, 2007; Javadian \& Singh, 2012; Safavi, 2013). We know little about experiences of women working in low-skilled jobs except from the findings of a limited number of studies on women home-based work such as handicrafts and carpet weaving. Yet unlike taxi driving such home based work are considered femaledominant indoor jobs (Z. Karimi, 2011; Modarresi, Arasti, Talebi, \& Farasatkhah, 2016, 
2017). Driving a taxi as an emerging career path within a highly male-dominant industry has remained understudied, which leads us to our first question "What are the nuances of FTDs' emergent career within a male-dominant context?"

\section{Boundarylesss Career and Independent Contract Work}

Taxi drivers work as independent contractors (Occhiuto, 2017; Quinlan \& Mayhew, 1999) — whose sequence of work experiences is independent from an employer — and can be categorized as boundaryless career actors (Arthur \& Rousseau, 1996; Parker, 2002).

Theoretical writings have introduced contract work as a growing type of boundaryless career (Arthur et al., 2017; DeFillippi \& Arthur, 1994). However, very few studies have empirically examined contract workers' careers; examples are limited to a study of freelancers including interim managers, journalists, and coaches (Van den Born \& Van Witteloostuijn, 2013) and leased executives (Parker, 2002). These studies provide initial support that independent contract work is closely related to the core idea of a boundaryless career: independence from an employer and traditional career arrangements.

To examine our participants' careers, we adopt the intelligent career framework, which is grounded in the boundaryless career perspective. The intelligent career framework was originally developed to describe the experiences of contract, contingent, and nonstandard workers in the knowledge economy where the use of internet and technology grows rapidly (DeFillippi \& Arthur, 1994). Recent products of the knowledge economy are digital platforms such as Upwork, Uber, Airbnb, or Etsy that build on the ubiquity of mobile devices to connect workers and customers independent of organizations (Manyika et al., 2016). The intelligent career framework enables researchers to examine career experiences of a new pool of independent contract workers - in our case the internet-based taxi drivers — who have emerged as a by-product of digital markets. 
An intelligent career encompasses three ways of knowing concerned with why, how, and with whom people work (DeFillippi \& Arthur, 1994, 1996; Parker et al., 2009). Broadly defined, why reflects the motivation to work and career identity; how is concerned with jobrelated skills and knowledge; and with whom addresses work relationships and networks (Arthur, Claman, \& DeFillippi, 1995; Arthur et al., 2017). In keeping with our qualitative approach, we adopted the three ways of knowing after conducting our data analysis (Merriam, 2009). We reviewed the contemporary career models (Hirschi, 2012) and found why, how, and with whom to be most compatible with the emergent categories in our findings. Adopting the intelligent career framework accommodated our "theory-data alignment" — where the theoretical framework fits the data—recommended in qualitative research (Köhler, 2016, p. 411; Pratt, 2009, p. 860).

To date, empirical research based on the intelligent career framework has taken an elite approach concentrating on professional career actors such as executives (Guptill, Reibling, \& Clem, 2018; Janasz, Sullivan, \& Whiting, 2003; Lee, 2018), academics (Aytekin, Erdogmus, Erdil, \& Akgün, 2016; Beigi, Shirmohammadi, \& Arthur, 2018), and expatriates (Cappellen \& Janssens, 2008; Suutari \& Mäkelä, 2007). The professionals studied by preceding researchers have been exclusively university graduates whose careers required high investments in education or professional training and reflect high motivation to build skills and knowledge in a self-directed career approach. A synthesis of previous findings suggests that the why to work sought in professional positions relate to professional identification, motivation for decision making, career progression, and search for challenge (Cappellen \& Janssens, 2008; Guptill et al., 2018). The how competencies developed in professional positions relate to investing in specialized knowledge and skills, learning, and openness to experience (Culié, Khapova, \& Arthur, 2014; Van den Born \& Van Witteloostuijn, 2013). In terms of with whom to work, past findings indicate that professionals rely on networks within 
and beyond their employers to advance in their careers (Chen \& Doherty, 2013; Guptill et al., 2018). These trends may or may not extend to nonprofessionals. Therefore, we extend this scholarship by focusing on nonprofessionals and answering the question of "What constitutes a boundaryless career as experienced by nonprofessional independent contract workers?"

\section{Boundarylesss Careers and Institutional Context}

Contemporary career literature increasingly emphasizes an understanding of careers in their contexts (Chudzikowski et al., 2011; Khapova \& Arthur, 2011; Mayrhofer et al., 2007; Tams \& Arthur, 2010). The boundaryless career literature so far has theoretically posited that careers cannot be understood independent of their institutional context. Yet, very few empirical studies have examined the role of institutions in the construction of a boundaryless career (Guan, Arthur, Khapova, Hall, \& Lord, 2019; Tams \& Arthur, 2010). Notable exceptions are Ituma and Simpson's (2009) study of IT professionals in Nigeria and Afiouni's (2014) work regarding female academics in Lebanon, which have highlighted the institutional constraints imposed on those pursuing a boundaryless career. These studies provide primary evidence that an understudied context has a high potential to reveal the effects of institutions on an individual's career and add to the conventional knowledge about boundaryless careers. As Bamberger and Pratt (2010) have established, focusing on understudied contexts and samples allows a study to discover novel aspects of a phenomenon.

In this study, we borrow from the institutional logics perspective, which proposed that contemporary society comprises market, state, family, and religion (Friedland \& Alford, 1991; Thornton et al., 2012). These institutions make logics available to individuals and organizations and shape their behaviors (Friedland \& Alford, 1991). Logics are comprised of material practices and symbolic systems such as values and beliefs that provide meaning to individuals' and organizations' daily activities (Thornton et al., 2012). Institutions such as family and religion each have a core logic that determine which behaviors are appropriate in 
the respective social setting. Therefore, the institutional logics perspective helps in locating individual and organizational behavior in their social context (Friedland \& Alford, 1991).

We realized that the institutional logics perspective explains our findings while analysing the data. Since we adopted it after our data collection, we use an inductive definition of institutional logics similar to many previous empirical studies and categorize them as constraining and driving forces (Reay \& Jones, 2016). Constraining forces describe institutions' capacity to impose boundaries (e.g., legal and cultural) to control and restrain behavior (Scott, 2014). Driving forces mean — aside from constraints—institutions provide resources and guidelines, which facilitate action (Scott, 2014). Researchers studying institutional logics with an inductive approach ground their definitions and abstractions in the context through participant quotations and thick description (Reay \& Jones, 2016). After our inductive analysis, we drew upon the existing discussions on the role of institutional factors in a boundaryless career (Baruch \& Vardi, 2016; Guan et al., 2019; Inkson, Gunz, Ganesh, \& Roper, 2012; Zeitz, Blau, \& Fertig, 2009) to further analyze the contextual situations in our study. In doing so, we seek to answer the question "How do institutional forces impact the boundaryless career of nonprofessional independent contract workers?"

\section{Methods}

\section{Methodology}

In this study, we adopt an interpretive qualitative approach. The interpretive approach is based on social constructivism and assumes that multiple realities are constructed by different individuals as a result of their different interactions with the same social phenomenon (Crotty, 1998). It strives to provide thick descriptions and context-bound working hypotheses, rather than testing hypotheses and generalizing study findings (Lincoln \& Guba, 1985). Specific to our study, the social constructivism lens facilitates the analysis of how careers and the social contexts are intertwined (Cohen, Duberley, \& Mallon, 2004). 


\section{Participants}

We adopted a purposeful sampling technique to select our participants who had rich and in-depth information (Patton, 2002). Our participants were 34 FTDs who worked at least 20 hours per week as an internet taxi driver in Tehran, the capital city of Iran. The average age of our interviewees was $41.9,44.1 \%$ were married with an average of 1.5 children, $29.4 \%$ were divorced with an average of 1.1 children, $8.8 \%$ were widowed with an average of 1.7 children, and $17.7 \%$ were single or in a relationship without children (Appendix 1). To recruit participants, we booked an internet taxi via the company's app, met the FTDs in their car and asked them not to launch the trip, and shared our research purpose and participant information sheet with the FTD. If they agreed to participate in the study, we asked them to cancel the trip, read and sign the consent form, and participate in the interview. To compensate their time, we gave the participants gift cards that covered the taxi fare for 90120 minutes.

\section{Data Collection}

We conducted semi-structured interviews to collect data for this study. The interviews were recorded with the permission of the participants and were kept in a password-protected nonpublic file. One of the authors, an academic based in Tehran, conducted all the interviews; however, another author, who was born and raised in Tehran, but was based in the UK and had not been in Iran when the internet taxies started working, joined her in one-fifth of the interviews to bring the outsider view and capture the dynamics of the participants' careers that might be taken for granted from an insider perspective. After conducting the first three interviews, we listened to the interview recordings, discussed what questions we might need to add to the interview protocol, and added two questions to the interview protocol (questions 9 and 10 in Appendix 2). Questions 1-2 focused on the FTDs' demographics and daily routines, questions 3-10 centered on our participants' experiences and perceptions as a 
taxi driver, and the final two questions asked for their additional relevant input. We reached saturation - a point where we found no new information in the setting (Hesse-Biber \& Leavy, 2010; Patton, 2002) — after conducting 26 interviews, but we interviewed eight more FTDs to ensure no new categories were emerging.

Thirty-two interviews were held in the participants' cars, one interview was conducted in a coffee shop, and one interview took place in a participant's house during daytime in Tehran. The collected data was in Farsi language, the official language in Iran. We used professional transcribing services to transcribe the interviews, which resulted in 614 pages of text (font size 12, single-spaced).

\section{Data Organization and Analysis}

We used the constant comparative method as our primary data analysis technique (Lincoln \& Guba, 1985). The constant comparative method includes coding incidents for a category and then comparing them with other incidents in all categories (Erlandson, Harris, Skipper, \& Allen, 1993; Lincoln \& Guba, 1985). We read through each interview transcript, coded it for units of meaning and assigned each unit an open code (using the exact words of the participants) (Merriam, 2009). In the next step, we brought together the units of meaning or codes relating to the same content into categories (Lincoln \& Guba, 1985).

Our data analysis was an ongoing process during which we constantly met, discussed our ideas, and moved between the data and the literature (Jackson \& Mazzei, 2012). We started our study with a focus on the FTDs' career as unfolded in their context; we did not decide about our theoretical lens until after conducting half of the interviews. Our team listened to each interview and open-coded them independently as soon as they were conducted. We virtually met as a team every week, compared our codes and discussed the theoretical lenses that could explain the experiences of our participants. 
We examined our independent codes and our emerging categories against multiple career perspectives (e.g., Hirschi, 2012) and finally selected the intelligent career framework (DeFillippi \& Arthur, 1996; Parker et al., 2009), as it could accommodate the majority of the codes we had generated during the process. Our codes led us to believe that we needed to capture the nuances of the institutional forces as they affected the FTDs' careers. Therefore, in addition to the intelligent career framework, we selected the institutional logics perspective (Friedland \& Alford, 1991; Thornton et al., 2012) to help us explain our findings with regards to the institutional forces.

In the next stage, we transferred our open codes to one document and had discussions to reach an agreement where we disagreed. Then, we used the Microsoft Excel software to organize our data analysis (because NVivo software did not support the Farsi language) and proceeded to categorize the open codes. We were all native Farsi speakers and analyzed the data without translating the transcripts. Our analysis resulted in fourteen categories that reflected the why, how, and with whom of the FTDs, as well as five institutional constraining forces, and seven institutional driving forces (Figure 1).

To present our findings, we asked a professional translator fluent in Farsi and English to translate our selected quotations to English. To ensure validity, we shared the translated quotations with an editor and worked with her to double-check the translations and make sure the translated quotations reflected the original tone of our interviewees.

\section{Trustworthiness}

Informed by Lincoln and Guba (1985), we adopted four strategies to ensure trustworthiness of our work. First, we kept a shared reflexive journal to reflect on the research process and to record our thought processes during the study. Second, we asked a qualitative researcher colleague who was not involved in the process to give us feedback on the findings. Third, we asked five FTDs to verify the accuracy of the findings and 
interpretations and determine whether the analysis represented their experiences (Appendix 3). Finally, we interviewed four male internet taxi drivers, as disconfirming samples (Patton, 2002), and inquired about their experiences as a taxi driver (Appendix 4). Our disconfirming sampling occurred after the initial data collection to put boundaries around our study's findings (Morrow \& Smith, 2000; Patton, 2002) and confirm that our findings are specific to our sample, FTDs.

\section{Findings}

We present our findings supported by representative quotations from the interview transcripts translated verbatim from Farsi to English. We have only reported the categories that were mentioned by at least 11 participants, which is approximately one-third of the interviewees. Due to the inseparability of the narrations of the three ways of knowing and the institutional logics that impacted them, we decided to present the normative and structural constraining and driving forces as we are narrating the why, how, and with whom categories to help readers gain a more realistic understanding of the examined careers embedded in their institutional context. To make it clear, we italicize the institutional forces when referring to them in our descriptions; Figure 1 summarizes our findings.

Insert Figure 1 about here

It is important to note that our findings unfolded in the city of Tehran (Picture 1) as the immediate work context for our participants, which had a role in the way they made sense of their careers. Tehran, with its dense urban population (over 8.52 million), intensive traffic (seventh out of 185 worldwide), increasing female employment, centrality to the country's economy, and modern technological infrastructure (Davachi, 2017; Kamali Dehghan, 2015; Taravat, Rajaei, \& Emadodin, 2017) provided a meeting ground of dynamics that made the driving career possible for women. 
Insert Picture 1 about here

Why

Our participants worked for a variety of reasons, the most common of which were financial needs, flexibility, passion for driving, independence, providing extra support to children, and having social relationships. At first glance, our categories seem to be common among all taxi drivers regardless of their gender, ethnicity, and place of residence. However, as our categories unfold in our descriptions of the findings, it becomes evident that institutions such as family, culture, economy, and religion play a major role in our participants' career trajectories.

Financial needs. All but three of our participants mentioned that fulfilling their financial needs was a motivator for deciding to work as a taxi driver. Of the FTDs, $17.7 \%$ had no prior work experience, $11.8 \%$ had professional jobs, and $70.5 \%$ had scattered job experiences occasionally working in temporary jobs including beauty-salon assistant, amateur tailor, secretary, cashier, and domestic worker, which are female-dominant jobs for women without college degrees in the country. The FTDs were happy that the internet-based taxi company had given them access to a platform that enabled them to earn money on a daily basis and when needed. As FTD26, who had been a taxi driver for more than a year and had started working in different jobs due to her husband's addiction 12 years prior to the interview, put it, "thank God, there's a way [to make a living], God bless those who founded such a company, because you know that, when you run out of money, there's a way to make some."

In many cases (13 participants), the financial needs experienced by our participants were caused by getting a divorce or having been widowed from a husband who had been the 
family's main breadwinner. Religious ${ }^{1}$ and cultural norms in the country give a husband's voice in his wife's career decisions, which had stopped or discouraged many FTDs from working while married. Our participants, the majority of whom came from working class families, asserted that their husbands either did not like them to work or constrained them from selecting a profession in which a female needs to have constant conversations with male strangers. For example, FTD $_{25}$, who started working as a driving instructor after divorce shared with us, “[When I was married,] my husband didn't like me to work... But when I got divorced, I was forced to choose this job, not following my heart, but to make ends meet." Another cause of financial needs mentioned (or alluded to) by the FTDs was the economic hardship experienced by Iranian families partially attributed to the economic sanctions against $\operatorname{Iran}^{2}$ (Levs, 2012). Our interviews coincided with the United States' decision to leave the agreement between the two countries and restoring the sanctions that were lifted for a few years (Borger, 2018). Some of our participants shared with us that initially they were not keen or their husbands did not allow them to work outside home, but their family was finding it hard to manage, which led to their decision to work as a taxi driver. As stated by FTD 13 ,

My husband is completely against me working... He's biased against women working. It's been some years since I have worked ..., because of the bad economic

\footnotetext{
1. Some Islamic narrations state that women should not leave their home without their husbands' permission. Leaving home in these narrations is expressed in an absolute form, which can mean leaving the home for study, work or any other reason (Al-Saduq, 1988). 2. The United States has imposed sanctions against Iran for decades, starting in 1979. The most recent wave of sanctions started in 2006 , when the United States and the European governments worked together to impose various sanctions on Iran (Columbia.edu, 2017). In 2010, the efforts increased by compelling foreign companies and banks to withdraw from Iran and customers that bought Iranian oil. The result was a 1.4 million barrel per day decrease in Iranian oil exports - the main source of country's income-compared to pre-sanctions levels (Columbia.edu, 2017). 2013 was the beginning of a brief period during which it seemed this trend was going to be reversed as the United States and Iran negotiated a deal suspending most of the sanctions (Columbia.edu, 2017). However, the sanctions were re-imposed in 2018
} (Borger, 2018). 
condition... Now, the situation is even worse ... [before I started working,] we had difficult times paying the rent and [our children's] university tuition ... but now... We don't have such difficulties.

Not all the FTDs were from Tehran, but all of them resided in Tehran and many of them expressed that they preferred to work in Tehran due to a potential for higher income in the capital city, demand for female-only taxies, and acceptance for diversity in Tehran.

Demands for taxis and the fares in a major city, Tehran in our case, are higher than small cities because the population, cars on the roads, and city boundaries continually increase, and some commutes within the boundaries of the city itself may take several hours and public transportation means are inadequate (Turnstyle, 2017). Application-based taxies, in which passengers book their taxies online and do not share the ride, offer reasonable prices. Many women prefer and feel safer when having a female driver and a more affordable taxi, which leads to a demand for female-only taxies.

In addition, as a modern and ethnically diverse city, the capital has more capacity for accepting differences and normalizing new practices. For example, FTD3, who had started working after getting a divorce, asserted:

Tehran is a very ... established city. In small cities, people may not agree with women doing such jobs, they don't find it acceptable but in Tehran, things are different. When you do something, before long, it will be accepted... But in small cities, I don't believe things would work this way... [And besides,] in Tehran, the fares are much higher.

The majority of our participants $(67.6 \%)$ believed in the traditional division of labor in families—women are the caregivers and men are breadwinners (Pleck, 1977)—and preferred to stay home and take better care of their children, themselves, and their household chores if they were economically well off. This was illustrated in response to our question 
about the probability of continuing to work as a taxi driver in case of not having any financial needs:

Yeah, anyway working is hard; if I had a source of income ... I wouldn't work at all... Then, I'd go to the gym, get some exercise, I'd take trips ... I would stay home, taking care of my children, their health. $\left(\mathrm{FTD}_{4}\right)$

Financial independence. Half of the FTDs enjoyed the financial independence brought to them by earning money. Those who were financially dependent on their husbands or families prior to becoming a taxi driver and were pressed for money liked their ability to "have their hands in their pockets" (e.g., FTD 20$)$ and "stand on their feet" (e.g., FTD 27$)$, instead of relying on their husband or someone else. Some of them enjoyed the fact that they could pay their debts $\left(\mathrm{FTD}_{23}\right)$, and were not forced to borrow money from others to make a living (e.g., FTD 18, FTD $_{32}$ ). Others liked being able to buy things that their husbands did not approve $\left(\mathrm{FTD}_{30}\right)$ or could not afford (e.g., FTD $\left._{14}\right)$. For example, $\mathrm{FTD}_{29}$, who was divorced with unemployed grown-up children, put it as below:

I went through depression when I got divorced, then I had to wait for my parents' support. I didn't feel comfortable asking them for this and that ... Then one day, in desperation I got a newspaper ... Oh God, what should I do...? I saw this company's ad and called, and not long after, started my job.

Providing extra financial support to children. Iran can be described as having a child-centric family culture in which socialization of younger generations has changed to more child centered, where parents are directly or indirectly receptive to be influenced by their children's desires, needs, and goals (Khosravan, Salehi, Ahmadi, \& Sharif, 2010), as evident in our interviews. Due to the high value of education in the culture, many high school graduates are encouraged to enter university, even if it means parents must work extra hours, 
or put themselves under pressure by spending less money for themselves or incurring debts they need to pay back. During university years, they typically stay with and are funded by their parents unless they need to move to another city to study, in which case most parents fund their housing and other costs as well as the university costs. Unfortunately, to some extent, this trend has led to credentialism or over emphasis on academic or other formal qualifications by employers and ordinary Iranians (Malekzadeh, 2015).

Due to the high demand for university degrees in Iran, entering public, government funded universities that require their graduates to pay back only a limited amount of money after securing a job is extremely competitive. The alternative is studying at private universities. Many participants were working to support their children's degrees, and a few were even saving up or incurring debts to support their children's study abroad.

Several FTDs were willing to sacrifice many things so that their children could live an easy or sometimes even a luxurious life. FTD 14 told us that she worked 14-hour days to pay for her expenses and fund her son's expensive bodybuilding expenses; FTD27, who was widowed and had previously done crochet and needle work to support her two children, said her son had most of the things he wanted including the latest version of PlayStation and other gadgets. When we asked the FTDs if their grown-up children in their twenties worked to support the family, many of them said that they only wanted their children to study and not to end up in low-skilled jobs like their own. For example, FTD 21 , who was widowed and, despite her certificates, had not been able to work before her husband passed away, said:

I do nothing for myself ... I had thyroid removal surgery, it was cancerous ... The doctor told me to follow-up every three months, ... I didn't ... not even [once]... I've always told myself to stand strong and keep going for the sake of my children ... seeing their success is enough for me... I send my daughter to the gym, giving her a 
ride back and forth, but I've never stepped in myself, during the hours that she works out, I'd work.

Due to the high rate of unemployment in Iran (Basravi, 2018), in many cases, our participants' children with university degrees remained unemployed, and the family continued to support them. Gaining bachelor's or higher degrees increases graduates' employment expectations (e.g., Taylor, 2007), and in many cases, they are not willing to accept low-skilled jobs. This was true for our participants' children with university degrees as well; $\mathrm{FTD}_{4}$ provides an example:

When my children studied at university ... every semester, I had to pay a check for their tuition, as well as other expenses. After getting their degrees, [they couldn't find jobs] ... they came to me and said we want to get our master's. I said fine ... It seems all I earn must go directly into the university's pockets.

Participants with grown-up children who were married or planned to marry had paid or were preparing to pay for their marriage costs, which is additional evidence for the childcentric family culture. In Iran, those who have girls are usually expected to pay the whole dowry that includes all the things needed in a married household; those with boys traditionally pay for their weddings — which sometimes have hundreds of guests — in addition to housing or financial support for housing.

Flexibility. Having flexibility was another common motivator for becoming an internet taxi driver among our participants. The FTDs enjoyed the fact that they could manage their workload and work hours without having to fulfil certain performance goals. This feature of the job allowed them to remain aligned with the traditional division of labor in their families and plan their work hours in such a way that it enabled them to take care of the household chores and caring responsibilities. In most cases, when their children or their family members were sick or needed special attention, the FTDs could be there for them. 
Many participants, especially those with children, left work midday or finished their jobs early to feed their family, cook or clean. For instance, FTD $_{1}$, whose husband was retired and stayed at home, asserted:

[Today] I took my daughter to work at 7 [am]... [then] I turned the device on and accepted riders till about 12:30 [pm]. I went back home around $1[\mathrm{pm}$,$] this is how I$ was raised. My mom used to be like this, my sister is also the same ... I feel like it's my duty to cook lunch, prepare dinner, and my husband has got used to this. Lunch and dinner must be always prepared, and God forbid, if this doesn't happen, it's the end of the world. He'd start arguing that you don't care about our life and you're always out.

Due to the negative attitudes towards female drivers-stereotypes that women are incompetent drivers whose driving cannot be trusted (Yeung \& von Hippel, 2008), driving a taxi belongs to lower social classes (Anderson, 2013), and is a male-dominant job (Roche et al., 2016) — some participants had decided to keep their work a secret from certain individuals and either served in neighbourhoods that were less likely to have passengers from their extended family or friends, or did not discuss their job with them. In those cases, their flexible work hours allowed them to show up for the afternoon parties they were invited to, or to stop working when they felt their jobs could be revealed to others. FTD , who was a single mom, expressed:

They look down on a woman who drives a taxi. In my family, only one of my sisters and my mom know about this. I kept it from my neighbours. I have two daughters. If others find this out, they would belittle my daughters and say your mom is a taxi driver. They look down on women who drive. This hurts me.

Passion for driving. Passion for driving was another common motivator among the FTDs. Twenty-one $(61.8 \%)$ of our interviewees enjoyed driving and were happy that this job 
allowed them to drive and earn money. Many had taken opportunities to work with schools to give rides to schoolchildren prior to becoming a taxi driver or alongside it. Our participants asserted that driving allowed them to have a sense of comfort (e.g., FTD 11 ) and feel free as evidenced below:

I love driving ... I think this car is my only true friend, because when I'm driving, I'm the real me ... My car is the only thing I enjoy being with, I talk to my car quite often, just like a friend. $\left(\mathrm{FTD}_{3}\right)$

In Iran, the first driving licence for women was issued approximately eight decades prior to this study and the first female taxi driver was licenced in 1940s. However, traditionally Iranian working-class families owned one car with the male members of the family being the main preferred drivers, which might partially justify the great passion for driving among our participants.

Having social relationships. Having the opportunity to meet passengers from different walks of life was a motivator for the FTDs. They liked talking to their passengers, hearing different stories, and learning about their experiences. A few FTDs had limited social relationships or had experienced depression (e.g., $\mathrm{FTD}_{28}$ ) and working as an internet taxi driver had given them a reason to leave home and come out of their comfort zone as evidenced below:

You know ... When you get to work ... You forget all the concerns you have at home ... I like to be active out in the world ... I prefer working outside rather than staying home ... I get to know people, ... I learn from their experiences ... their stories ... $\left(\mathrm{FTD}_{1}\right)$

For some participants, this job was among the few jobs that allowed them to play a role in the society despite the religious or cultural constraints for women employment. A few jobs, such as working as a girls' school teacher (the schools are gender-divided in Iran), 
would have given them such opportunities, but in most cases our participants lacked the required credentials. As FTD 22 stated, “I always liked working, but I didn't insist ... My [first] husband didn't like it... After the divorce, I decided to go to work ... well, this job was the only thing I could do."

\section{How}

The FTDs highlighted the importance of developing a set of skills and setting some conditions for how they worked. Some categories were generic skills needed for taxi drivers with contingencies specific to our participants, but the conditions were more culturally driven. On average, the participants had received their driving licence 14 years prior to starting their jobs but not all of them had extensive driving experience, and many FTDs developed such skills for the job or on the job.

Preferring female passengers. Most FTDs (67.6\%) preferred to serve female passengers for a variety of reasons including their personal preference or not having permission from their husband. Initially, the internet-based taxi company assigned only female passengers to female drivers, while male drivers served both genders, but later the company allowed female drivers to receive requests from both female and male passengers with the option of rejecting male passengers without being penalized for it. The internetbased taxi company had reduced its commission from female drivers to offer lower taxi fares to customers who selected female drivers as a means to motivate more passengers to ask for them. This cultural alignment, especially the option to accept passengers according to their preferences, was valued by our participants. Some FTDs felt insecure when giving rides to male passengers due to their fear of victimization and harassment - of possibly being sexually harassed and physically attacked while working alone and sharing a small space with strangers (Westmarland \& Anderson, 2001). The company did not set and male passengers did not follow any strict rules for sitting in the front or back, which raised some 
issues for the FTDs who gave rides to male passengers. Some FTDs did not feel at ease when male passengers gazed at their body $\left(\mathrm{FTD}_{22}\right)$ and some did not feel safe with the close proximity between them and a male passenger sitting in the front. Participants who had harassment memories from their previous jobs or from male passengers developed strategies (e.g., putting a big object on the front seat) for avoiding such negative experiences.

Driving skills. The majority of our participants (79.4\%) emphasized the importance of driving skills in their job, asserting that they were competent drivers and that they rarely had any driving-related issues. FTDs' confidence in their driving, as reflected in the interviews, stemmed from their performance, as well as from their institutionalized beliefs. When describing their driving skills, some participants used confirmation of male passengers as evidence for their skills. Some participants even used men's driving as a standard against which they compared themselves: "I kinda drive like men, and it's been a long time since I sat behind the wheel, maybe twelve or thirteen years... My driving is not bad; no one has ever complained so far" (FTD 11$)$.

Improving navigation skills. Tehran is a big city, with an area of $281.9 \mathrm{mi}^{2}$, and many participants $(73.5 \%)$ had to develop their navigation skills to be able to serve their customers (Arsanjani, Helbich, \& de Noronha Vaz, 2013). Using GPS has not been common in Iran; $3 \mathrm{G}$ and $4 \mathrm{G}$ internet access in recent years enabled the FTDs to use WAZE, which is a navigation software common there, and a few similar navigation apps. Some participants were comfortable asking for directions, and some had spent time improving their navigation skills in order to avoid asking for directions. FTD15, who had worked in several low-skilled jobs prior to becoming an internet taxi driver, remembered, "I had navigation problems ... I made so many mistakes, but it got ok... finding directions is not a routine for women, but men are usually good at it, all in all, I'm ok with it now." 
Becoming masculine. When referring to how they worked, some FTDs (32.4\%) asserted that being a taxi driver required them to become masculine or to lose their femininity to a certain degree; a few confirmed the traditional division of labor and found working outside their home to be a man's job that their current situation forced them to do. When we asked the FTDs to clarify what they meant by becoming masculine or less feminine, they came up with two overlapping descriptions for some of the participants: (a) changing some behaviors or stopping to do things that they perceived to be associated with femininity, and (b) starting to do things or adopting certain behaviors that they perceived to be linked to masculinity. FTDs, in many cases, regarded their job as a "Man's job" (FTD 31 ) that required them to "act like a man" (FTD18). For example, our participants referred to driving confidently and fast $\left(\mathrm{FTD}_{19}\right)$, being serious $\left(\mathrm{FTD}_{24}\right)$, filling the tank $\left(\mathrm{FTD}_{7}\right)$, or changing a punctured tire $\left(\mathrm{FTD}_{16}\right)$ to be men-only jobs. They thought their job required them to become “thick-skinned," which they did not consider feminine. As FTD 3 put it,

... if women work, it drops their womanliness... Working destroys lady qualities, that dignity, that elegance. It makes you stern, tough... It keeps you away from being a lady... Say, painting the nails, you let it go because nails get damaged at work anyway... Or say, taking care of your look to be a lady ... it doesn't work. I do feel sorry for us who lose our womanliness and elegance this way... Working makes them tough, makes them like men, unfortunately.

Accessing a car. Although accessing a car is necessary for any driver, it had many contingencies among our participants and in the institutional context of our study. Due to the high import tax for cars and the high rate of inflation in Iran, the dynamics of buying a car is different from the typical process experienced in Western or developed countries. For example, the price of the cheapest Kia Motors car, Pride, which was \$2,200 in 2017 and $\$ 3,692$ in 2019 , is approximately 2.6 times more than Iran's 2019 minimum annual salary of 
$\$ 1,400$. Our participants partially associated the increased car prices with recent economic sanctions against Iran and highlighted that due to their high prices, it is not easy to buy or replace a car for working class families, and the life cycle of cars is very long.

To access a car, the FTDs who did not own a car borrowed money, obtained high interest bank loans, or shared a car with the other drivers in the family (which could be challenging). The internet-based taxi company banned using cars older than seven years, which required some participants to replace their old cars with a new car.

Developing self-protection strategies. The majority of the participants had security concerns when providing service in certain areas (e.g., suburbs) or to certain individuals (e.g., passengers who looked suspicious). Security concerns and fear of victimization and harassment affected how they navigated their careers. Some FTDs limited their service to certain areas of Tehran and avoided serving passengers travelling to suburbs or nearby cities. This meant they partially sacrificed their income to address their security needs. For example, FTD9, who was among the four FTDs who had professional jobs in addition to being an internet taxi driver, had a boyfriend who was constantly alert and in touch with her by phone to make sure she was safe. $\mathrm{FTD}_{28}$, gave us an example that illustrates how her religious beliefs were enacted when feeling in danger:

I don't take passengers everywhere... Once I took a lady to [a suburban area] and from there a man requested a trip to Chitgar, [which is a forest park outside the city], and I made the mistake of accepting the trip ... He looked weird and smelled cigarette ... I was so afraid that I vowed ${ }^{4}$ five [thousand] Tomans ${ }^{5}$ to remain safe.

Some participants changed their car's front windows to smoke colors that did not allow outsiders to see inside the car, prepared to defend themselves by carrying defensive

\footnotetext{
4. What a person is obliged to give in the cause of God (Amid, 2002).

5. Almost half of the taxi fare earned in the trip.
} 
tools, or rejected passengers who seemed suspicious. FTD 19 share with us, "My car's doors are always locked, I've also tinted the windows so others can't see the inside... But sometimes I wish I had something to defend myself... a pepper spray, shocker, or something... although they are illegal to carry."

Some FTDs told us that even their passengers or their family members reminded them of the dangers and the fear of victimization and harassment in nonurban areas outside Tehran: I often don't work after $7[\mathrm{pm}]$ or $8[\mathrm{pm}] \ldots$ for safety reasons ... it might be a male passenger and who knows? ... He can put a knife to your throat and mug you. Once, I had a chat with a journalist, she said ... please don't work when it gets dark... Even the male passengers who get in my car say the same thing. (FTD 17 )

\section{With Whom}

Internet-based taxi company. Most FTDs felt that they owned their job; however, they were registered with the internet-based taxi company, had received a short training from them, accessed their database to secure customers, and gave a certain percentage of their taxi fares to them. The internet-based taxi company supported the FTDs when they had issues with the customers, which played an important role in the FTDs' careers and helped them feel more secure. Among the other supports the FTDs received from the internet-based company was being paid when a customer refused to pay (e.g., FTD $9, \mathrm{FTD}_{32}$ ) and feeling secure due to being tracked by the company's GPS (e.g., FTD 17 ). When caught in a harassment situation, such as passengers saving the FTDs' phone numbers and sending them inappropriate texts (e.g., FTD28) or trying to touch them while driving (e.g., FTD 12 ), the FTDs informed the company, which then blocked the customers out of their system, as described below:

Once, I had a male passenger and after I took him to his destination, he kept texting ... I am in love with you and all ... I replied what do you mean? What are you talking about? But he didn't leave me alone, so I had to call the company to follow-up 
on it. I sent his number and texts to the company. Fortunately, the problem was resolved after blocking him five times $\left(\mathrm{FTD}_{1}\right)$

Passengers. The FTDs' jobs and income were highly dependent on their passengers who paid for the fare and evaluated their performance through giving them stars after each trip. Passengers could create positive or negative experiences for the FTDs and motivate or demotivate them to continue the job. Due to the significant role of passengers in the FTDs' jobs, we asked the FTDs about critical incidents they had with passengers since starting the job. Our participants were generally satisfied with the majority of the passengers, but almost all of them had experienced both positive and negative critical incidents.

The FTDs asserted that in various cases, many passengers made them feel good about themselves and motivated them by giving complements or paying more than expected. The majority of the complements the FTDs received were either for their driving skills, or for choosing to be a taxi driver. Our participants shared with us that many passengers complemented them for choosing to be a taxi driver and dealing with the difficulties of the job like a man, as opposed to being dependent on men or acting similar to some other women. The FTDs clarified for us that these complements indirectly referred to women who earned money through sex work or being in unethical relationships with men.

In some cases, passengers, typically men, paid more than the taxi fare showed on the app as a means of showing respect for what the FTDs were doing:

[I had a passenger who] had paid the fare online, but he offered me extra money [when he got off] ... he said ... we are proud of women like you who try to earn money to support their families and children." $\left(\mathrm{FTD}_{27}\right)$

The negative incidents experienced by the FTDs were mainly due to the negative attitudes towards female drivers. For example, the FTDs preferred their female passengers to sit in the front, but many female passengers did not meet their expectation. When female 
passengers chose not to sit in the front, the majority of the FTDs interpreted it as being perceived as private drivers. FTD5, was very angry about such cases:

The other day, I had a [female] passenger I said come sit in the front ... she refused! Go to hell! Sit wherever you like. I turned the conditioner on to make you feel more comfortable it was for your own good... Then, you look down on me with such behavior?

In other incidents, female passengers expected the FTDs to do things that were beyond their responsibilities or that they were banned from doing on their job (e.g., allowing passengers to smoke). Asking the FTDs to drop them at a spot different from the one selected in the app and having unplanned stops mid-way were among other requests the FTDs could not accommodate, as they were not paid for them, but many passengers, typically female, asked for them, as confirmed in the two quotations below:

A woman told me the other day "I asked for a driver to carry my stuff and put them in the car!" Who are you? What the hell ... She just treated me like I am nothing ... There's no reason we treat others like this, we've got to ease each other's pain, not add to them. (FTD 14$)$

Oh, some women... The first thing they do ... is to light a cigarette... Oh God, how should I tell them that you can't do so, this is the rule of the company ... no smoking ... And then when I ask them politely to stop smoking, they get mad at me. (FTD 3$)$

A few FTDs, who accepted passengers from both genders, said that some male passengers immediately cancelled their trip after learning that the driver will be a female. Refusing to accept female drivers could be attributed to the negative attitudes towards female drivers or cultural concerns as described below:

I once picked up a guy, he said ... why did they send me a woman driver? ... he said it does not look good [if a woman driver drops me off] ... Once we got there, as soon 
as he stepped off the car ... two guys saw him and sneered: "Good for you Haji ${ }^{6} \ldots$ you hang out with the angels now!" (FTD 8$)$

Family. Another group with whom the FTDs managed their careers were their family members including their children, spouses, parents, and siblings. FTD23, who had decided to hide her job from her son-in-low and his family, was supported by her daughter:

I kept this from my son-in-law and his family for quite a long time, ... finally my daughter reacted, she said that "Mom, your job makes us proud, why are you hiding it?" ... before that I used to turn my device off [when close to my daughter's home] so as to prevent picking a relative by accident ... I was worried how they would react ... thank God, my children supported me in this very much.

Aligned with the culture of the country, the FTDs received support from their parents and in some cases their siblings, continuing after marriage. Depending on the situation, they helped with childcare $\left(\mathrm{FTD}_{27}\right)$, paid for their rent $\left(\mathrm{FTD}_{29}\right)$ or groceries $\left(\mathrm{FTD}_{17}\right)$, paid for their insurance (FTD 12), provided accommodations (FTD 14 ), or allowed them to use their car (FTD $29, \mathrm{FTD}_{32}$ ). Receiving such support enabled the FTDs to continue working and putting up with the low income of the job.

Citizens. Although the FTDs had no problem driving, many of them did not feel comfortable changing a tire or fixing their car when stopping in the middle of a highway; however, this did not interrupt them from doing their jobs, as they were supported by male drivers who volunteered to help them when in need. In Iran, there is a cultural tradition of men helping stranger women when in need in public. For example, if a woman is carrying a heavy weight, pushing a car for a jumpstart, or changing tires, typically, a man will rush to help. This was the case in difficult driving situations:

6. It refers to a Muslim who has been to Mecca as a pilgrim and a religious man. 
Men come help when your car is broken ... they definitely help ... be it changing a flat tire ... charging a battery ... pushing your car ... you car is stuck and all of a sudden you see ten men help pushing ... our country's men are awesome! (FTD8) Our analysis of the four interviews with male taxi drivers demonstrated that other than four institutional driving forces that are common among all the citizens (economic hardship, potential for higher income in the capital city, high value of education, child-centric family culture, and traditional division of labor), the rest of the institutional forces were specific to the FTDs' careers. With regards to the three ways of knowing, obviously we could not reach saturation after four interviews, but other than financial needs and flexibility (why), which mainly centred on driving a taxi after being made redundant or deciding to take an additional job, none of the sub-categories presented the FTDs' accounts in Figure 1 emerged in the analysis of our interviews with male taxi drivers. For example, none of the interviewed men mentioned having a passion for driving (why), improving their navigation or driving skills (how), or receiving support from the internet-taxi company or citizens (with whom); however, more research is needed to examine male internet taxi drivers' career and provide an in-depth description of their experiences and contingencies.

\section{Discussion}

This study set out to unpack an understudied career in an unconventional context. Through studying the FTDs' career experiences, we provided insights into independent contract work within the emerging internet-based taxi driving industry. Furthermore, within the boundaryless career literature, ours is one of the few empirical studies exploring independent contract workers' careers.

Our work challenges existing literature focusing on professionals and identifies new elements comprising the three ways of knowing (why, how, and with whom) specific to nonprofessionals' careers. We provide empirical evidence to bridge the gap in the 
boundaryless and intelligent career literatures regarding the role of institutions in constructing such careers. Further, the inductive approach we adopted to examine our research's understudied context revealed the driving and constraining institutional forces shaping the components of three ways of knowing. As a result, our findings provide ample examples of how normative and structural institutional logics—-stemming from family, religion, economy, and culture — shape individuals' career contingencies.

We contribute to the existing literature by highlighting new reasons characterizing the knowing why dimension of the intelligent career framework. Previous studies have assumed a sense of achievement, desire for challenge, autonomy, and professionalism as the "why" of seeking independent contract work (Parker, 2002; Van den Born \& Van Witteloostuijn, 2013). Our study, however, draws attention to the critical role that financial needs play as a dimension of "why" and as a motivation to seek contract work. It is intriguing that financial motivation has not been addressed because it also plays an important role for both professional and nonprofessional contractors (Kalleberg et al., 1997). Furthermore, our findings highlight the role of institutional forces in shaping a contextual meaning of financial needs. For example, our participants made sense of their need to improve their children's future lives driven by a child-centric family culture in the context of economic hardship. Similarly, financial independence for our sample meant self-reliance apart from husband or family, instead of independence from an employer by professionals.

Another example of the contextual meaning of the "why" dimension in our findings is flexibility. The existing literature suggests that male taxi drivers also mentioned flexibility as a desired feature of their job, but they used flexibility as a way to make sense of their difficult work situations (Occhiuto, 2017). The meaning of flexibility differed for the FTDs in our study due to the normative constraints (e.g., traditional division of labor), as in many cases it 
allowed them to satisfy domestic responsibilities or hide their work as a driver from those considering this job inappropriate for women (e.g., extended family or friends).

Interestingly, our findings regarding "why" pointed out to the facilitating role of the capital city. Although all our participants were based in Tehran, our findings and indicative quotations confirm that all of them were well aware of the opportunities brought to them by living and working in the capital city. Our participants emphasized that acceptance for diversity in Tehran, demand for female-only taxies, and potential for higher income in the capital city as well as the internet-based taxi company's adjustments with the culture by giving the FTDs the option of deciding not to give rides to male passengers, were among the reasons why they worked. Tehran, with its modern technological infrastructure, is often the first city in the country to host innovative practices such as the internet-based taxi companies - start-ups and web-based platforms. Other big cities in Iran are gradually moving towards adopting the same practices, but it is only after Tehran, the capital city, has normalized such practices and made it possible for the wave to move to other big cities, and later, to smaller cities as well. This can be considered significant progress for female employment in the country, specifically for those who do not have a college degree or are not highly skilled. It is important that future researchers take into account the role of developed environment (e.g., major cities versus rural and small cities) while studying the emerging internet-based careers adopted by nonprofessionals.

Our second theoretical contribution is the previously nonidentified factors related to "how." How in the existing intelligent career literature refers to specialized skills obtained through education, training and work experience, learning from successive projects, and being open to new ideas (Culié et al., 2014; Van den Born \& Van Witteloostuijn, 2013). Our findings support the learning component of how, as the FTDs had to learn and improve their driving and navigation skills. However, we suggest that for nonprofessionals such as the 
FTDs in our study, instead of special training, a degree, or previous experience, having access to their own work equipment is more crucial. Rather than knowledge and skills required to stay employable, the FTDs needed skills and strategies to protect themselves from city dangers (prefer female passengers and develop self-protection strategies) as well as to fit into the cultural mold and become masculine, as they put it.

How in our study suggests that for taxi drivers whose "workplace comprises physical places such as streets, highways, and taxicabs, and social places," careers take place in a city instead of in an organization (Facey, 2010, p. 1259). Since the FTDs work as independent contractors, they are the ones to define their relationship with the city and to set the boundaries for how they work in the city. Without an employer regulating their work, they are the owners of their careers and more likely to be influenced by the structural constraints present in a society rather than an organization. As described in the findings, due to fear of victimization and harassment, some FTDs decided to limit their passengers to females only, some abandoned certain destinations (e.g., suburbs) or districts with dense traffic (e.g., downtown), some limited their work hours to before dark, and some carried tools to protect themselves from harassment. The FTDs' boundaries on how they worked in the city were often based on trial and error learning or a direct experience.

The FTDs' boundary-setting raises a question about the benefits of independent contract work promoted by the boundaryless career perspective (Arthur et al., 2017). Since the FTDs worked as independent contractors, they were minimally protected against unpleasant work experiences, such as harassment and clients with negative attitudes and comments. As compared to those pursuing careers within and between organizations, the contractor is on her own to face the negative aspects of the job. Is independent contract work a double-edged sword — on the one hand, offering flexibility and independence, and on the other hand, less protection? This argument is supported by Uber drivers' recent protests to be 
recognized as employees by the law rather than contractors (Hawkins, 2018; Isaac \& Scheiber, 2016).

Our study contributes to the literature by identifying elements of "with whom" for nonprofessional as deviating from professional networking and centering on support. The intelligent career framework defines with whom as professional connections (e.g., colleagues inside and outside one's organization) (Arthur et al., 2017). The literature suggests that being an active networker, calling people, visiting business contacts, handing out business cards, and sending mail, cards, and gifts to individuals in the network contribute to objective career success for independent contract professionals (Van den Born \& Van Witteloostuijn, 2013). Although the FTDs worked as independent contractors, receiving support from the internetbased taxi company was critical in sustaining their careers as drivers-specifically, giving them the options to accept passengers aligned with their preferences and to block passengers after reported issues. We illustrate that nonprofessional contract work in male-dominant occupations calls for support mechanisms provided by the company, even though the employment contract is not permanent. Given that the work context for the FTDs was the city and not an organization, passengers and citizens emerged as those with whom the FTDs worked. Interestingly, instead of supervisors, colleagues or peers, it was day-to-day interactions with passengers and citizens that created positive or negative experiences for the FTDs.

Working independently of an employer, the FTDs had partial discretion in setting boundaries for with whom they preferred to work. Since the overall characteristics of the residents of each part of a big city might be different (Glaeser, 2011), the FTDs could set boundaries around the kind of people (passengers and citizens) they preferred to interact with during the day. For example, some worked only in affluent areas of the city (e.g., the northern parts of Tehran) where the culture typically welcomed women's employment and there was a 
higher probability of interacting with open-minded passengers. Such experiences were different from office-based employees who might not be able to have a voice in deciding on their work conditions or their customers, and were praised by many of our participants.

Our findings contribute to the current understanding of emerging internet taxi driving careers, especially for women. It is suggested that internet taxi drivers face precarity and risk (Malin \& Chandler, 2016); our study shows that women in need of financial resources and flexibility — especially those with children — may be drawn to internet taxi driving, despite its risk, whether in Tehran or any other country. Furthermore, we identify how the experience of internet taxi driving careers depends on institutional contingencies women face in their specific contexts.

We offer support for the notion that internet-based taxi services could be changing the male-dominant nature of taxi driving and opening up a niche for women, despite the barriers. Our findings identify the normative and structural constraints that women may face in this job. For example, the fear of victimization and harassment during their daily commutes is a common problem in countries with male-dominant cultures - especially in large cities (Dunckel-Graglia, 2013; Gekoski, Gray, Adler, \& Horvath, 2017). A popular reaction to this problem is female-only transportation services such as Pink taxies/buses in Mexico City (Dunckel-Graglia, 2013) and Flower subway cabins in Tokyo (Horii \& Burgess, 2012). Even with this potential solution, very few female-only transportation solutions are offered by female-drivers, since driving careers and the transportation industry are extremely maledominant (Roche et al., 2016). Internet-based taxi companies may be making the driving career available to women; however, our study shows that the fear of victimization and harassment may function as a structural career barrier. Further, traditional division of labor and a husband's voice in his wife's career decisions may also function as normative barriers to entering or maintaining such careers for women in countries with male-dominant cultures. 
The majority of institutional forces we found were normative (four out of five constraining and five out of seven driving forces), which stemmed from societal institutions such as family, religion, and culture. The current debates about the role of institutions in a boundaryless career have predominantly discussed institutions' structural support (e.g., career counselling, certification, and labor market assistance, Zeitz et al., 2009) and structural constraints (e.g., organizational policies, labor market segmentation, and social class, Guan et al., 2019). Our work complements this literature by highlighting driving (e.g., demand for female-only taxies) and constraining (e.g., negative attitudes towards female drivers) forces that have received limited scholarly attention in contemporary career literature. In addition, career scholars have been encouraged to present a balanced view of boundaryless careers that includes its positive and negative aspects (Baruch \& Vardi, 2016; Inkson et al., 2012), which is addressed in our work.

Specifically, regarding future research, we would recommend that scholars concentrate on the continued operationalization and measurement of why, how, and with whom. We suggest future quantitative researchers add items to the existing scales of the three ways of knowing (Eby, Butts, \& Lockwood, 2003) to capture contingencies of the boundaryless career being studied. As an example, Jokinen, Brewster, and Suutari (2008) supplemented Eby et al. (2003) scale with additional items to capture "ability to link resources and activities internationally" (p. 988) while studying expatriates.

Currently the "why" scales focus on openness to experience, proactive personality, and career insight (Eby et al., 2003). We suggest adding items such as "I seek to ensure financial security through my work" or "I seek to provide for my family," to capture financial needs, and "I seek flexibility to organize my daily schedule," to quantify flexibility. To assess "how," current scales have primarily relied on career identity, continuous learning, diversity, and transferability of job-related skills (Eby et al., 2003). Based on our findings, we 
recommend items such as these be added: "I seek to access/own equipment required for my job," "I am learning strategies to protect myself against risks and dangers involved in my job," and "This job is making me act masculine." "With whom" categories have been commonly assessed by items about the breadth of an individual's network outside of an organization (Eby et al., 2003). We suggest future researchers acknowledge the important role of relationships with family members, customers, and the broader community, especially in the case of independent contractors whose work is detached from organizational settings. Sample items could be "I develop relationships with my clients," "I feel supported by people in my family," and "I feel supported by people in the community." Items we suggested above comply with the intelligent career framework and partly overlap with components of the Intelligent Career Card Sort exercise (ICCS®) — the original activity designed to elicit the three ways of knowing (Arthur et al., 1995; Arthur et al., 2017).

\section{Limitations and Implications}

One of the limitations of our study is that we conducted one round of interview and could not capture our participants' perceptions of their career experiences over a longer period of time; for example, some of the normative and structural constraints might be removed as this job becomes more popular in the country. In addition, the average tenure of our participants as a taxi driver was 16.66 months, which might be regarded as low. The FTDs perceptions and experiences might change over time; for example, they might not be as passionate about driving if they practice this job for a longer period.

Due to the qualitative nature of our study, our findings cannot be generalized to other career contexts (Merriam, 2009). However, individuals with attributes similar to our participants and women who plan to pursue a driving career with internet-based taxi companies might consider our findings as a road map for planning their careers. For instance, we have suggested that the flexibility and independence in this career fits women who need 
to fulfil traditional family roles, or those who need to work for financial reasons, or those with low-level skills and education. These women can obtain driving and navigation skills without extensive time or financial investments and can satisfy their personal and family financial needs. Internet-based taxi companies need to align their services with institutional logics in a country context to make it feasible for females to work as drivers. Our findings highlight the importance of internet-based companies' support for female drivers, such as GPS tracking, blocking passengers with harassment records, and giving the option to women to cancel a ride if they decide not to drive a male passenger. These companies can advance support mechanisms for female drivers by facilitating peer communities and training self-defence skills. We recognize that our participants belong to a generation of women who may have reinforced the effects of institutional normative constraints, such as the traditional division of labor. The effects of such constraints may differ for younger generations of women choosing to be taxi drivers. We conducted this study at the early life stages of internet-taxi companies in Iran. The meanings the FTDs make of their careers may change over time as more women enter this career, and as they create a community with a culture of its own.

This paper responds to the need for improving our understanding of a boundaryless career in its context, illuminating the role of structural and normative forces constraining and driving nonprofessional independent contract workers' careers. Our research contextualizes the meaning of the three ways of knowing for nonprofessionals and female drivers in a Muslim-dominant country. As a complementary finding, this paper shows that internet taxi drivers' work experiences unfold in a city rather than an organization. In the absence of an employer to regulate their work, drivers own their careers and are impacted by institutional logics existing in their career context. These findings advance our knowledge of contemporary careers in an understudied context. 


\section{References}

Afiouni, F. (2014). Women's careers in the Arab Middle East: Understanding institutional constraints to the boundaryless career view. Career Development International, 19(3), 314-336.

Ahmad-Nia, S. (2002). Women's work and health in Iran: a comparison of working and nonworking mothers. Social Science \& Medicine, 54(5), 753-765.

Al-Saduq, A. S. (1988). Man la yahduruhu al-faqih. Tehran: Sadouq Publishing.

Amid, H. (2002). Amid dictionary. Tehran: Amirkabir publication.

Anderson, E. (2013). Streetwise: Race, class, and change in an urban community. London: University of Chicago Press.

Arsanjani, J. J., Helbich, M., \& de Noronha Vaz, E. (2013). Spatiotemporal simulation of urban growth patterns using agent-based modeling: The case of Tehran. Cities, 32, $33-42$.

Arthur, M. B., Claman, P. H., \& DeFillippi, R. J. (1995). Intelligent enterprise, intelligent careers. Academy of Management Perspectives, 9(4), 7-20.

Arthur, M. B., Khapova, S. N., \& Richardson, J. (2017). An intelligent career: Taking ownership of your work and your life. Oxford: Oxford University Press.

Arthur, M. B., \& Rousseau, D. M. (1996). The boundaryless career. Oxford: Oxford University Press.

Aytekin, I., Erdogmus, N., Erdil, O., \& Akgün, A. E. (2016). Academicians' Career Capital and Career Satisfaction: The Mediation Effect of Research Productivity. Educational Sciences: Theory and Practice, 16(6), 1921-1945.

Bahramitash, R., \& Hooglund, E. (2011). Gender in contemporary Iran: Pushing the boundaries: Taylor \& Francis. 
Bahramitash, R., \& Salehi Esfahani, H. (2009). Nimle Fingers No Longer! Women's Employment in Iran In A. Gheissari (Ed.), Contemporary Iran: economy, society, politics: Oxford University Press.

Bamberger, P. A., \& Pratt, M. G. (2010). Moving Forward by Looking Back: Reclaiming Unconventional Research Contexts and Samples in Organizational Scholarship. Academy of Management Journal, 53(4), 665-671. doi:10.5465/amj.2010.52814357

Baruch, Y., \& Vardi, Y. (2016). A Fresh Look at the Dark Side of Contemporary Careers: Toward a Realistic Discourse. British Journal of Management, 27(2), 355-372. doi:10.1111/1467-8551.12107

Basravi, Z. (2018). Iran unemployment crisis, rising living costs bite amid sanctions. Retrieved from https://www.aljazeera.com/news/2018/08/

Beigi, M., Shirmohammadi, M., \& Arthur, M. (2018). Intelligent career success: The case of distinguished academics. Journal of Vocational Behavior, 107, 261-275.

Bond, A. T. (2014). An app for that: Local governments and the rise of the sharing economy. Notre Dame Law Review Online, 90, 77-96.

Borger, J. (2018). Trump administration to reimpose sanctions on Iran. The Guardian. Retrieved from https://www.theguardian.com/world/2018/nov/02/

Boyd, C. (1997). 'Just like one of the boys': Tactics of women taxi drivers. In P. Greenhill \& D. Tye (Eds.), Undisciplined Women: Tradition and Culture in Canada (pp. 213222). Canada: McGill-Queen's University Press.

Bricke, M. K. (2008). The Islamic Republic's Women at the Wheel. Retrieved from $\underline{\text { http://content.time.com/time/world/article/0,8599,1847151,00.html }}$

Cappellen, T., \& Janssens, M. (2008). Global managers' career competencies. Career Development International, 13(6), 514-537. doi:10.1108/13620430810901679 
Carson, B. (2018). Where Uber Is Winning The World, And Where It Has Lost. Retrieved from https://www.forbes.com/sites/bizcarson/2018/09/19/

Chen, A., \& Doherty, N. (2013). The perceptions of an EMBA experience in China: an exploratory study. Journal of Management Development, 32(7), 780-795.

Chudzikowski, K., Ogliastri, E., Briscoe, J. P., Ituma, A., Reichel, A., Mayrhofer, W., \& Khapova, S. (2011). Culture and context: Understanding their influence upon careers. In J. P. Briscoe, D. T. Hall, \& W. Mayrhofer (Eds.), Careers and Cultures: Individual and Contextual Perspectives (pp. 147-165). New York: Routledge.

Cohen, L., Duberley, J., \& Mallon, M. (2004). Social constructionism in the study of career: Accessing the parts that other approaches cannot reach. Journal of Vocational Behavior, 64(3), 407-422.

Columbia.edu. (2017, July 21). Brief History of US Sanctions on Iran. Retrieved from https://energypolicy.columbia.edu/research/brief-history-us-sanctions-iran

Cramer, J., \& Krueger, A. B. (2016). Disruptive change in the taxi business: The case of Uber. American Economic Review, 106(5), 177-182.

Crotty, M. (1998). The foundations of social research: Meaning and perspective in the research process. London: Sage.

Culié, J.-D., Khapova, S. N., \& Arthur, M. B. (2014). Careers, clusters and employment mobility: The influences of psychological mobility and organizational support. Journal of Vocational Behavior, 84(2), 164-176.

Dastmalchian, A., Javidan, M., \& Alam, K. (2001). Effective Leadership and Culture in Iran: An Empirical Study. Applied Psychology, 50(4), 532-558.

Davachi, A. (2017, May 24). What Iranian Women Want. Retrieved from https://www.usnews.com/news/best-countries/articles/ 
DeFillippi, R. J., \& Arthur, M. B. (1994). The boundaryless career: A competency-based perspective. Journal of Organizational Behavior, 15(4), 307-324.

DeFillippi, R. J., \& Arthur, M. B. (1996). Boundaryless contexts and careers: A competencybased perspective. In M. B. Arthur \& D. M. Rousseau (Eds.), The boundaryless career: A new employment principle for a new organizational era (pp. 116-131). UK: Oxford University.

Dunckel-Graglia, A. (2013). Women-only transportation: How “pink” public transportation changes public perception of women's mobility. Journal of Public Transportation, 16(2), 85-105.

Eby, L. T., Butts, M., \& Lockwood, A. (2003). Predictors of success in the era of the boundaryless career. Journal of Organizational Behavior, 24(6), 689-708.

Erlandson, D. A., Harris, E. L., Skipper, B. L., \& Allen, S. D. (1993). Doing naturalistic inquiry: A guide to methods. Thousand Oaks: Sage.

Esbenshade, J., \& Shifrin, E. (2018). The Leased Among Us: Precarious Work, Local Regulation, and the Taxi Industry. Labor Studies Journal, 1-21.

Esbenshade, J., Shifrin, E., \& Rider, K. (2018). Leveraging liminality: how San Diego taxi drivers used their precarious status to win reform. Labor History, 1-17.

Facey, M. (2010). 'Maintaining Talk'among taxi drivers: Accomplishing health-protective behaviour in precarious workplaces. Health \& Place, 16(6), 1259-1267.

Forde, K. (2014). Hail to the ladies: NYC's first women-only taxi service. Retrieved from http://america.aljazeera.com/articles/2014/11/12/sherides-taxi-service.html

Friedland, R., \& Alford, R. R. (1991). Bringing society back in: Symbols, practices and institutional contradictions. In W. W. Powell \& P. J. Dimaggio (Eds.), The New Institutionalism in Organizational Analysis (pp. 232-263). London: The University of Chicago Press. 
Gaskell, A. (2017, January 26). The Impact Of Uber On The Taxi Industry. Retrieved from https://www.forbes.com/sites/adigaskell/2017/01/26/

Gekoski, A., Gray, J. M., Adler, J. R., \& Horvath, M. A. (2017). The prevalence and nature of sexual harassment and assault against women and girls on public transport: an international review. Journal of Criminological Research, Policy and Practice, 3(1), 3-16.

Gheissari, A. (2009). Contemporary Iran: economy, society, politics: Oxford University Press.

Ghorbani, M., \& Tung, R. L. (2007). Behind the veil: an exploratory study of the myths and realities of women in the Iranian workforce. Human Resource Management Journal, 17(4), 376-392.

Glaeser, E. (2011). Triumph of the City. New York: The Penguin Press.

Guan, Y., Arthur, M. B., Khapova, S. N., Hall, R. J., \& Lord, R. G. (2019). Career boundarylessness and career success: A review, integration and guide to future research. Journal of Vocational Behavior, 110, 390-402.

Guptill, M., Reibling, E. T., \& Clem, K. (2018). Deciding to lead: a qualitative study of women leaders in emergency medicine. International Journal of Emergency Medicine, 11(1), 47. doi:10.1186/s12245-018-0206-7

Hawkins, A. J. (2018, April 12). Uber drivers are freelancers, not employees, judge rules. Retrieved from https://www.theverge.com/2018/4/12/17231060/

Hesse-Biber, S. N., \& Leavy, P. (2010). The practice of qualitative research: Sage.

Hirschi, A. (2012). The career resources model: an integrative framework for career counsellors. British Journal of Guidance \& Counselling, 40(4), 369-383. doi:10.1080/03069885.2012.700506 
Horii, M., \& Burgess, A. (2012). Constructing sexual risk: 'Chikan', collapsing male authority and the emergence of women-only train carriages in Japan. Health, Risk \& Society, $14(1), 41-55$.

Inkson, K., Gunz, H., Ganesh, S., \& Roper, J. (2012). Boundaryless Careers: Bringing Back Boundaries. Organization Studies, 33(3), 323-340. doi:10.1177/0170840611435600

Isaac, M., \& Scheiber, N. (2016, April 21). Uber Settles Cases With Concessions, but Drivers Stay Freelancers. Retrieved from https://www.nytimes.com/2016/04/22/technology/

Ituma, A., \& Simpson, R. (2009). Theboundaryless' career and career boundaries: Applying an institutionalist perspective to ICT workers in the context of Nigeria. Human Relations, 62(5), 727-761.

Jackson, A. Y., \& Mazzei, L. A. (2012). Thinking with theory in qualitative research. New York: Taylor \& Francis.

Janasz, S. C. d., Sullivan, S. E., \& Whiting, V. (2003). Mentor networks and career success: Lessons for turbulent times. Academy of Management Perspectives, 17(4), 78-91.

Javadian, G., \& Singh, R. P. (2012). Examining successful Iranian women entrepreneurs: an exploratory study. Gender in Management: An International Journal, 27(3), 148-164.

Javidan, M., \& Dastmalchian, A. (2003). Culture and Leadership in Iran: The Land of Individual Achievers, Strong Family Ties, and Powerful Elite. The Academy of Management Executive (1993-2005), 17(4), 127-142.

Jokinen, T., Brewster, C., \& Suutari, V. (2008). Career capital during international work experiences: contrasting self-initiated expatriate experiences and assigned expatriation. The International Journal of Human Resource Management, 19(6), 979998. doi:10.1080/09585190802051279 
Kalleberg, A. L., Rasell, E., Cassirer, N., Reskin, B. F., Hudson, K., Webster, D., . . SpalterRoth, R. M. (1997). Nonstandard work, substandard jobs. Flexible work arrangements in the US: ERIC.

Kamali Dehghan, S. (2015, May 31). From Digikala to Hamijoo: the Iranian startup revolution. Retrieved from https://www.theguardian.com/technology/2015/may/31/

Kamali Dehghan, S. (2017, July 31). Snapp: how Tehran's answer to Uber is changing how people travel, and live. Retrieved from https://www.theguardian.com/cities/

Karimi, L. (2009). Do Female and Male Employees in Iran Experience Similar Work-Family Interference, Job, and Life Satisfaction? Journal of Family Issues, 30(1), 124-142. doi:10.1177/0192513x08324973

Karimi, Z. (2011). The effects of international trade on gender inequality in Iran In R. Bahramitash (Ed.), Veiled employment: Islamism and the political economy of women's employment in Iran (pp. 166-190): Syracuse University Press.

Khapova, S. N., \& Arthur, M. B. (2011). Interdisciplinary approaches to contemporary career studies. Human Relations, 64(1), 3-17.

Khosa, M. M. (1997). Sisters on slippery wheels: women taxi drivers in South Africa. Transformation(33), 18-33.

Khosravan, S., Salehi, S., Ahmadi, F., \& Sharif, F. (2010). A qualitative study of the impact of spousal death on changed parenting practices of Iranian single-parent widows. Iranian Red Crescent Medical Journal, 12(4), 388-395.

Köhler, T. (2016). From the Editors: On Writing Up Qualitative Research in Management Learning and Education. Academy of Management Learning \& Education, 15(3), 400418. doi:10.5465/amle.2016.0275

Lee, P.-Y. (2018). How to develop dynamic capabilities in multiunits: The roles of international experience and career capital. Management Decision, 56(2), 344-357. 
Levs, J. (2012, January 23). A summary of sanctions against Iran. Retrieved from https://www.cnn.com/2012/01/23/world/meast/iran-sanctions-facts/index.html

Lincoln, Y. S., \& Guba, E. G. (1985). Naturalistic Inquiry. Newbury Park, California: Sage. Malekzadeh, S. (2015). The new business of education in Iran.

Malin, B. J., \& Chandler, C. (2016). Free to work anxiously: Splintering precarity among drivers for Uber and Lyft. Communication, Culture \& Critique, 10(2), 382-400.

Mayrhofer, W., Meyer, M., \& Steyrer, J. (2007). Contextual issues in the study of careers. In H. Guntz \& M. Peiperl (Eds.), Handbook of career studies (pp. 215-240). Thousand Oaks: Sage.

Mehrkhane. (2017). Any news from Ladies Wireless Taxi? Retrieved from $\underline{\text { http://mehrkhane.com/fa/news/34173/ }}$

Mehrnews. (2015). 33.5 million driver's licences issued: Women's share is 17\%. Retrieved from https://www.mehrnews.com/news/2768954

Merriam, S. B. (2009). Qualitative research: A guide to design and implementation. JosseyBass: John Wiley \& Sons.

Metcalfe, B. D. (2006). Exploring cultural dimensions of gender and management in the Middle East. Thunderbird International Business Review, 48(1), 93-107.

Modarresi, M., Arasti, Z., Talebi, K., \& Farasatkhah, M. (2016). Women’s entrepreneurship in Iran: how are women owning and managing home-based businesses motivated to grow? International Journal of Gender and Entrepreneurship, 8(4), 446-470.

Modarresi, M., Arasti, Z., Talebi, K., \& Farasatkhah, M. (2017). Growth barriers of womenowned home-based businesses in Iran: an exploratory study. Gender in Management: An International Journal, 32(4), 244-267.

Moghadam, V. M. (2003). Modernizing women: Gender and social change in the Middle East. London: Lynne Rienner Publishers. 
Morrow, S. L., \& Smith, M. L. (2000). Qualitative research for counseling psychology. Handbook of counseling psychology, 3, 199-230.

Newall, S. (2015, December 17). Where are all the female cab drivers? Retrieved from https://www.independent.co.uk/news/uk/mad-friday-the-imbalance-between-male

Occhiuto, N. (2017). Investing in independent contract work: The significance of schedule control for taxi drivers. Work and Occupations, 44(3), 268-295.

Parker, P. (2002). Creativity in contract workers' careers. In M. Peiperl, M. Arthur, \& A. N. (Eds.), Career creativity: Explorations in the remaking of work (pp. 123-141). Oxford: Oxford University Press.

Parker, P., Khapova, S. N., \& Arthur, M. B. (2009). The intelligent career framework as a basis for interdisciplinary inquiry. Journal of Vocational Behavior, 75(3), 291-302.

Patton, M. Q. (2002). Qualitative evaluation and research methods. Thousand Oaks: Sage.

Pleck, J. H. (1977). The work-family role system. Social Problems, 24(4), 417-427.

Pratt, M. G. (2009). From the Editors: For the Lack of a Boilerplate: Tips on Writing Up (and Reviewing) Qualitative Research. Academy of Management Journal, 52(5), 856-862.

Quinlan, M., \& Mayhew, C. (1999). Precarious employment and workers' compensation. International journal of law and psychiatry, 22(5-6), 491-520.

Reay, T., \& Jones, C. (2016). Qualitatively capturing institutional logics. Strategic Organization, 14(4), 441-454.

Roche, A. M., Pidd, K., Fischer, J. A., Lee, N., Scarfe, A., \& Kostadinov, V. (2016). Men, work, and mental health: a systematic review of depression in male-dominated industries and occupations. Safety and Health at Work, 7(4), 268-283.

Safavi, F. (2013). Emerging Profiles of Female Marketing Managers in the Islamic Republic of Iran: Winning and Losing Competitive Laps in a Relay Race against Male Counterparts. International Journal of Marketing Studies, 5(3), 73. 
Scott, W. R. (2014). Institutions and organizations: Ideas, interests and identity. Thousand Oaks: Sage Publications.

Shatiel, J. (2016, May 18). More female cab drivers behind the wheel in NYC. Retrieved from https://www.amny.com/transit/more-female-cab-drivers-behind-the-wheel-in

Statistical Center for Iran. (2018). Summary of workforce statistics. Retrieved from https://www.amar.org.ir/Portals/0/News/1397/1_niroeyekar3-97.pdf

Suutari, V., \& Mäkelä, K. (2007). The career capital of managers with global careers. Journal of Managerial Psychology, 22(7), 628-648. doi:doi:10.1108/02683940710820073

Tams, S., \& Arthur, M. B. (2010). New directions for boundaryless careers: Agency and interdependence in a changing world. Journal of Organizational Behavior, 31(5), 629-646.

Taravat, A., Rajaei, M., \& Emadodin, I. (2017). Urbanization dynamics of Tehran city (1975-2015) using artificial neural networks. Journal of Maps, 13(1), 24-30.

Taylor, D. (2007). Employment Preferences and Salary Expectations of Students in Science and Engineering. BioScience, 57(2), 175-185. doi:10.1641/b570212

Thornton, P. H., Ocasio, W., \& Lounsbury, M. (2012). The institutional logics perspective: A new approach to culture, structure, and process. New York: Oxford University Press.

Turnstyle. (2017, December 06). Iranian Women Take the Wheel. Retrieved from https://www.huffingtonpost.com/turnstyle/

Van den Born, A., \& Van Witteloostuijn, A. (2013). Drivers of freelance career success. Journal of Organizational Behavior, 34(1), 24-46.

Westmarland, N., \& Anderson, J. (2001). Safe at the wheel? Security issues for female taxi drivers. Security Journal, 14(2), 29-40. 
Yeung, N. C. J., \& von Hippel, C. (2008). Stereotype threat increases the likelihood that female drivers in a simulator run over jaywalkers. Accident Analysis \& Prevention, 40(2), 667-674.

Zeitz, G., Blau, G., \& Fertig, J. (2009). Boundaryless careers and institutional resources. The International Journal of Human Resource Management, 20(2), 372-398.

doi:10.1080/09585190802670763 
Figure 1. Summary of findings

Institutional Constraining Forces

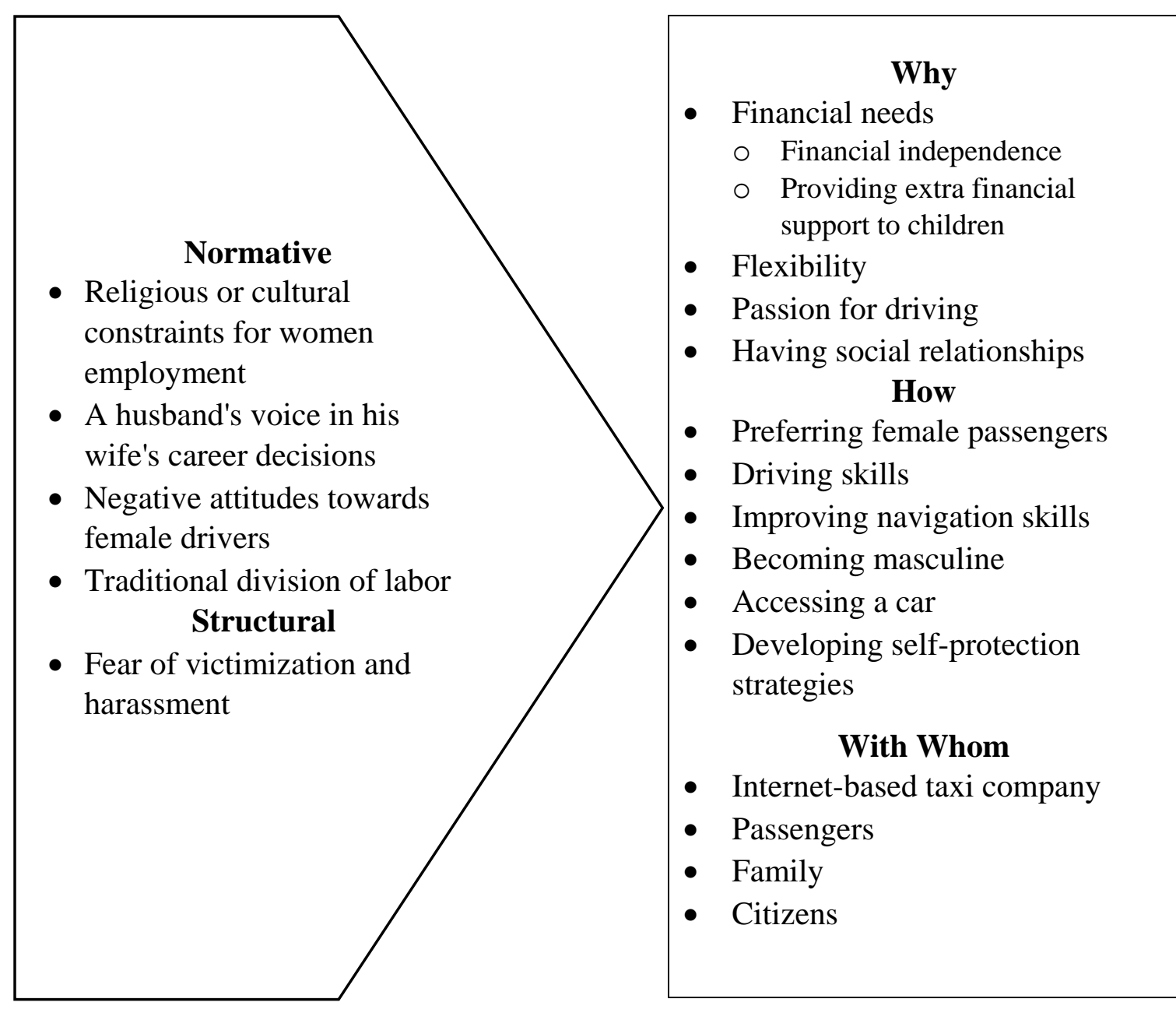

Three Ways of Knowing

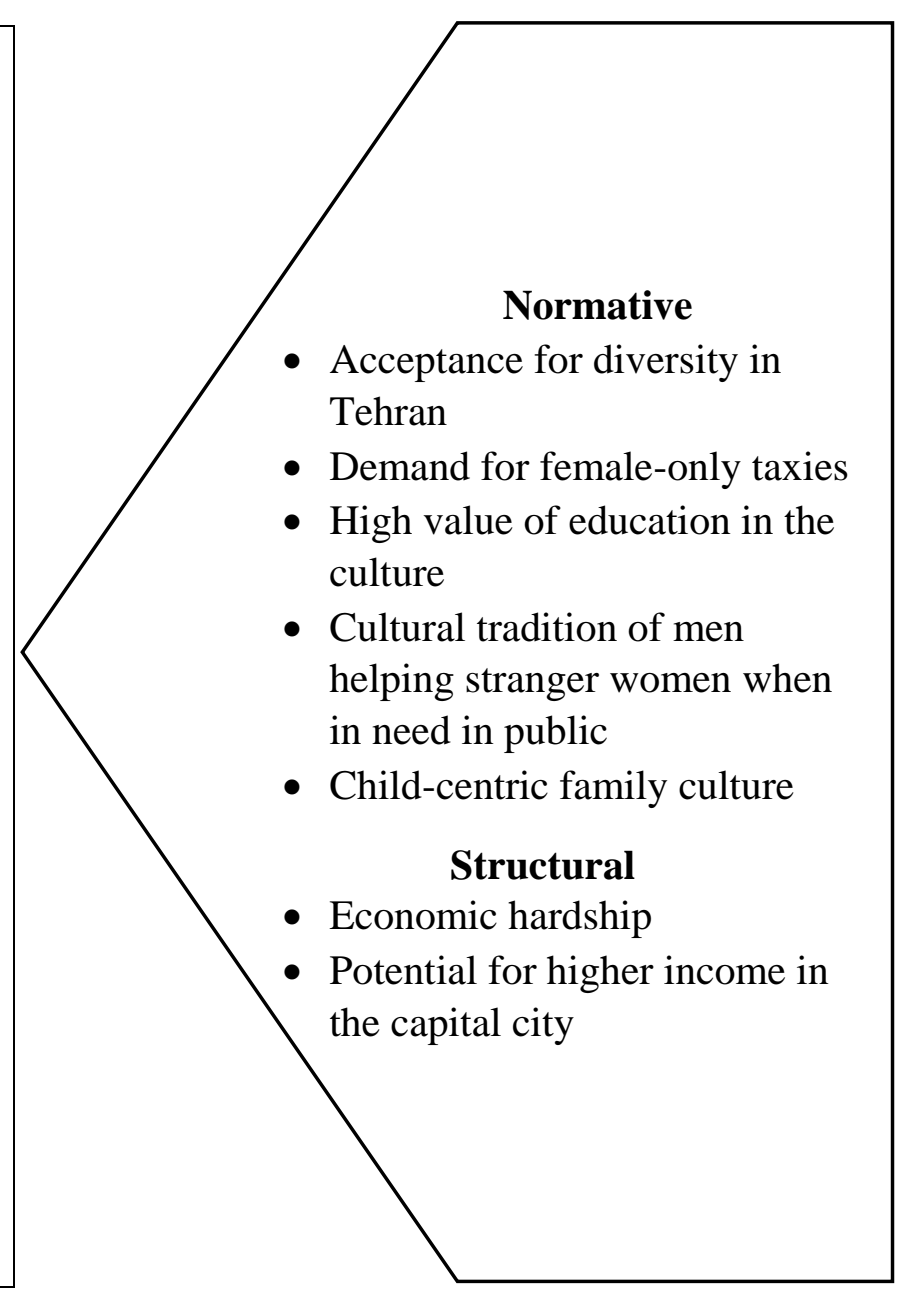

Institutional Driving Forces

Acceptance for diversity in

- Demand for female-only taxies

High value of education in the helping stranger women when in need in public

- Child-centric family culture

- Potential for higher income in the capital city 
Picture 1. Tohid Tunnel in Tehran, Iran, November 12, 2015

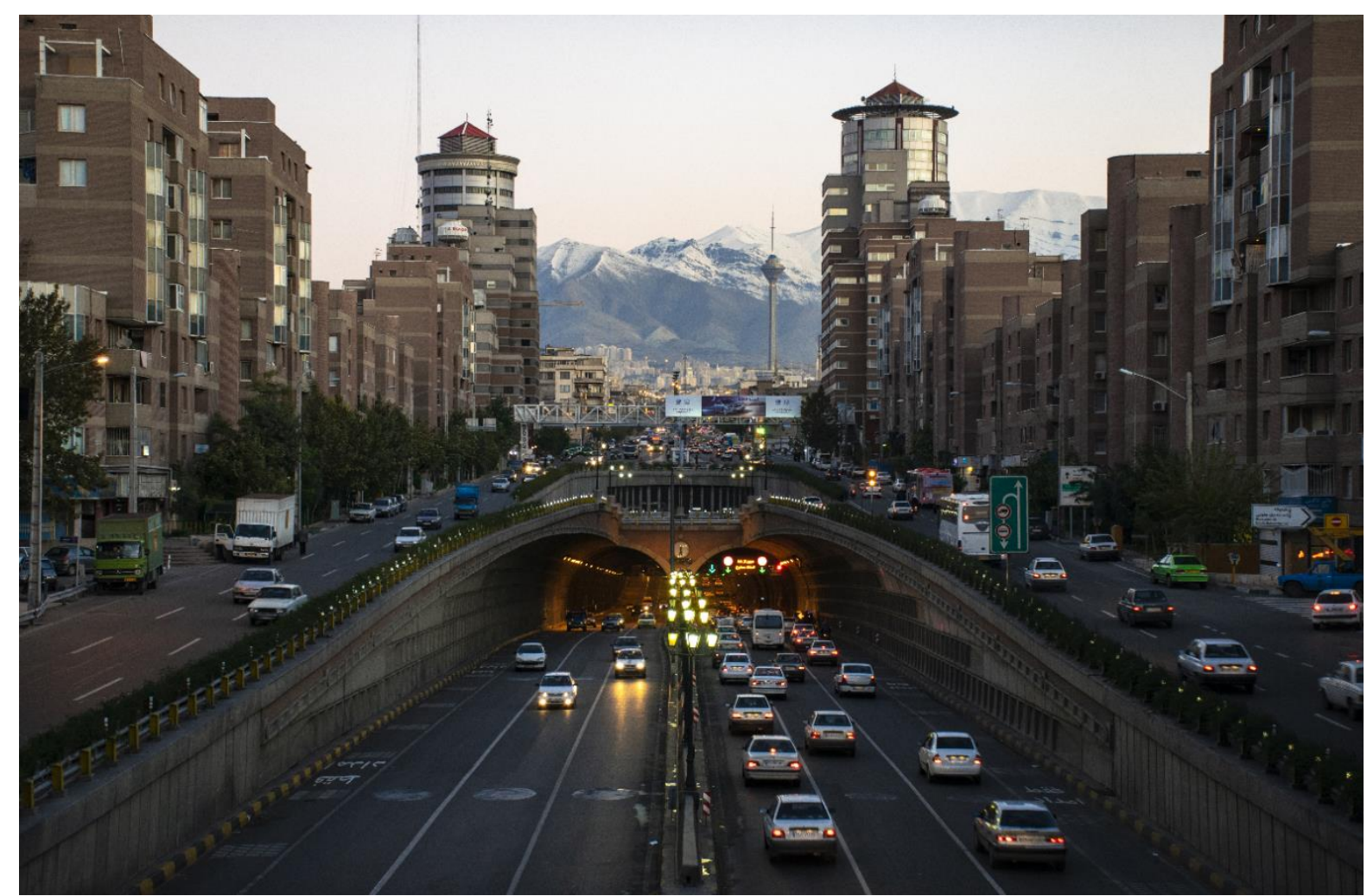

Photograph by Pooriya Alaedini 